\title{
Cold Denaturation of Proteins in the Absence of Solvent
}

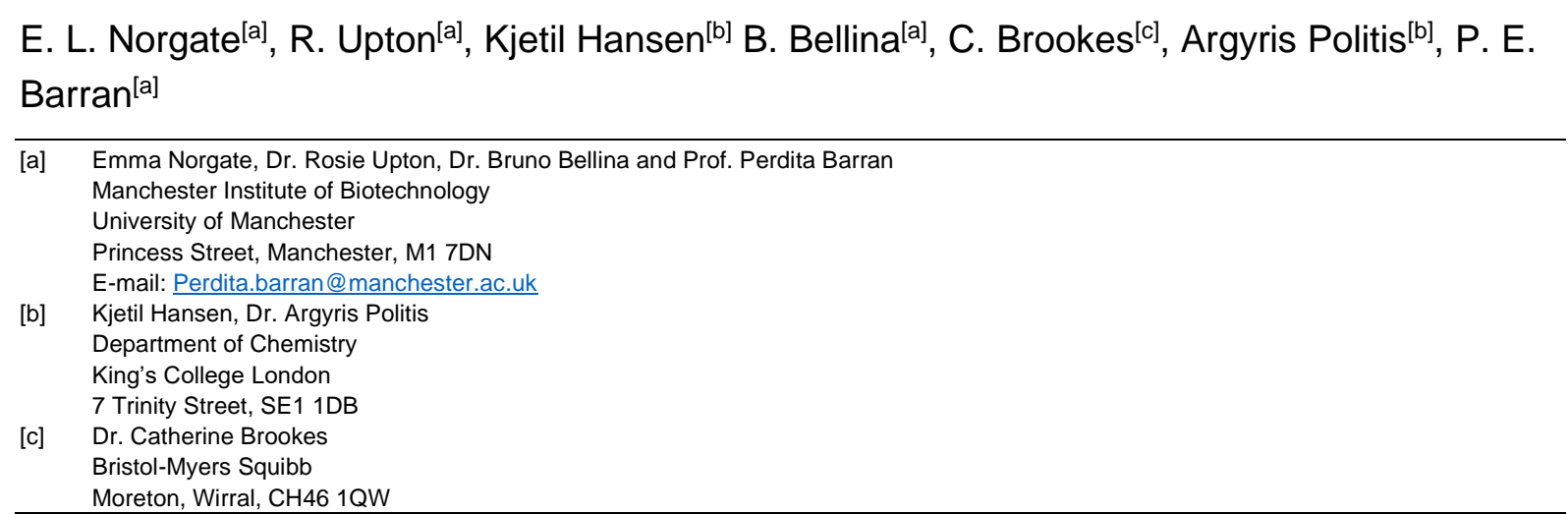

Supporting information for this article is given via a link at the end of the document.

The effect of temperature on the stability of proteins is well explored for high temperatures, but harder to track below the freezing point of water. This challenge is met with the use of variable temperature ion mobility mass spectrometry (VT IM-MS), which allows the structure of isolated, solvent free molecules to be measured at sub ambient temperatures in the form of their collision cross section (CCS). Here we monitor conformational changes that occur to two isotypes of monoclonal antibodies over a temperature range from 295 to $165 \mathrm{~K}$. For each we observe a large increase in the magnitude of the $\operatorname{CCS}$ at $250 \mathrm{~K}\left(-20^{\circ} \mathrm{C}\right)$ substantially above that predicted. This loss of structure in the absence of bulk solvent is attributed to a change in the strength of stabilizing intermolecular interactions, causing rearrangement. At $190 \mathrm{~K}\left(-80{ }^{\circ} \mathrm{C}\right)$ the $\mathrm{CCS}$ distribution narrows which we attribute to better resolution. These findings indicate that in vacuo deep-freezing minimizes denaturation and maintains the gas phase native fold supporting this practice in vitro. Comparing the data for each isotype suggests that the disulfide bridging influences thermal structural rearrangement and taken together we show that this method provides unique insights to the phenomenon of cold denaturation.

Cold denaturation is a phenomena whereby proteins' lose their tertiary and quaternary fold at low temperatures. ${ }^{1}$ In solution interactions between the solvent and the polar, hydrophilic groups on the exterior of the protein are in part responsible for maintenance of fold, as is the effect of polar solvent in driving hydrophobic groups to the protein interior. As the temperature of a polar solvent is lowered, 
solvent-solvent interactions start to dominate and form strong networks that lead in aqueous solutions to the formation of ice. The effect of this is to weaken the influence of the solvent on the structure of the protein, which in turn will perturb the dependence of the fold in having hydrophilic groups on the exterior and hydrophobic on the interior. The free energy difference between the folded and unfolded state is very small and these effects can reverse the stability, causing the protein to denature. ${ }^{2,3}$ For large proteins, formation of ice in interstitial spaces may add to the perturbation of the tertiary fold, although the overall influence of lowering temperature on protein structure will be dependent on the time it takes to freeze the system. ${ }^{1}$ The effect of cold temperatures on the stability of proteins has relevance to biotechnology, for example in the manufacture of enzymes that work at low temperatures, ${ }^{4-8}$ biopharma, in the storage and transport of therapeutics ${ }^{9,10}$ and in the effects of a changing climate on agriculture and animals. ${ }^{11,12}$

Very few experimental methods exist that can explore these effects, and yet, every protein biochemist is well aware that newly expressed proteins should be snap frozen to $-80^{\circ} \mathrm{C}$ to preserve their functional fold, rather than placed in a $-20{ }^{\circ} \mathrm{C}$ domestic freezer or fridge. By contrast, elevated temperature denaturation assays are a mainstay of biophysical evaluation of protein stability. ${ }^{13,14}$ The handful studies on the effect of cold temperature on protein stability involve the use of a denaturant to destabilise the protein to a point where cold denaturation occurs at higher temperatures. ${ }^{15}$ Alternatively, the use of high-pressure systems can be used to lower the freezing point of the water itself. ${ }^{16}$ However both these techniques inherently result in deviation of the protein from its native structure prior to the temperature being lowered, meaning the clarity between native and unfolded states is less distinct. ${ }^{17}$

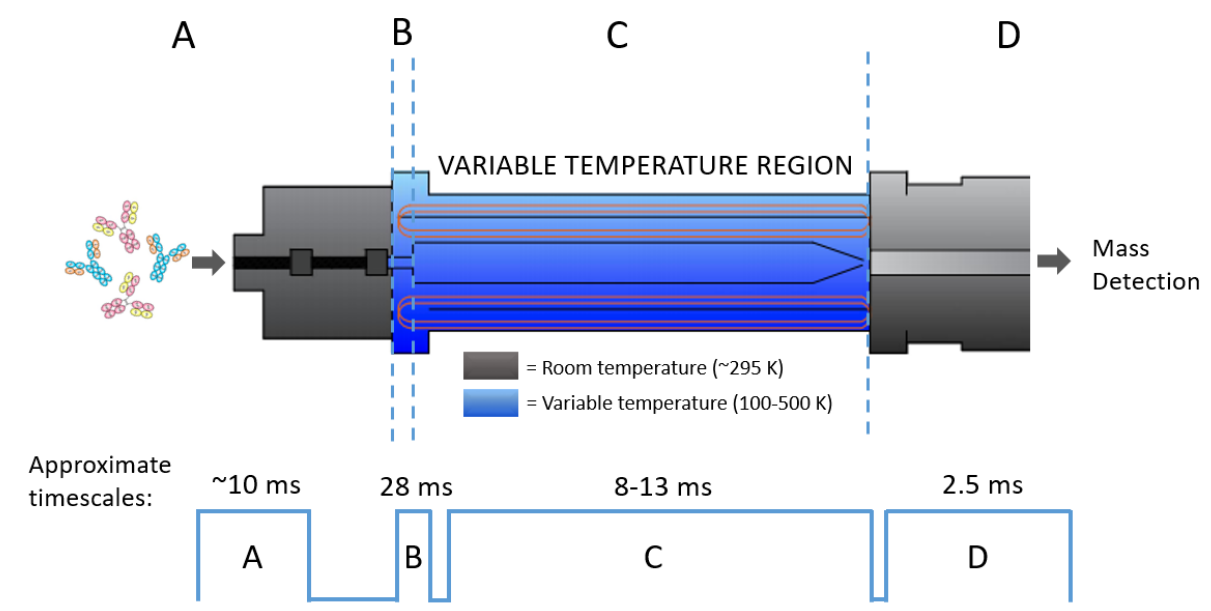


Figure 1. Schematic to show the mains stages of VT-IMS separation and the associated timescales. A: Protein sample enters instrument at room temperature via $\mathrm{nESI}$. Transfer from liquid to gas phase takes approximately $10 \mathrm{~ms} .{ }^{18} \mathrm{~B}$ : Protein ions are trapped forming spatially narrow "packets". The ions are trapped for up to $28 \mathrm{~ms}$ in the ion buncher in the presence of buffer gas, where they equilibrate to the buffer gas temperature. C: Packets of protein ions enter the drift cell where they drift for 8-13 ms and separation based on the mobility of the ions occurs. D: Ions are transferred to a ToF mass analyser at room temperature and detected in the form of mass resolved arrival time distributions which can be converted to CCS distributions.

IM-MS is uniquely positioned to study protein conformations and whilst most work is performed at ambient temperatures, there are instruments capable of measurements from $80 \mathrm{~K}$ to $600 \mathrm{~K}$ including the one used in this study (Figure 1). ${ }^{19-22}$ The collision cross section measured in all IM-MS experiments is temperature dependent ${ }^{23}$ and VT IM-MS instruments are able to measure both the effect of temperature on the structure of protein ions as well as the effect of temperature on CCS. Due to the increased influence of the long-range interactions at low temperatures, the CCS of a rigid ion will increase as the temperature is lowered. The resolution of ion mobility increases with $(\sqrt{ } T)^{-1}$ which means this approach could resolve conformers not possible at ambient temperatures. mAbs have an inherent flexibility away from the pivotal hinge and therefore are good target molecules to be examined by VT IM-MS. They exhibit broad CCS distributions consisting of several closely related conformational families. ${ }^{24}$ IM-MS has shown that it is possible to differentiate the conformational landscapes adopted by IgG subclasses/ isoforms as well as determine the impact of glycosylation on stability. ${ }^{24-27}$ VT IM-MS experiments on mAbs over an elevated temperature range $(300-550 \mathrm{~K})$ showed how these proteins unfold in vacuo. ${ }^{28}$ Here we seek to explore thermal induced conformational change below room temperature.

VT IM-MS measurements of IgG1, IgG2 and NIST monoclonal antibody (mAb) samples were performed on a home-built IM-MS instrument as previously described (Figure 1). ${ }^{29}$ In brief, ions are generated via nanoESI (source temperature $80^{\circ} \mathrm{C}$, capillary voltage $\sim 1.0-1.4 \mathrm{kV}$ ), and are guided by two ion tunnels towards an ion buncher which is located within the high pressure region helium ( 2 Torr) where they are accumulated prior to injection in the $50.5 \mathrm{~cm}$ drift region (Figure 1). The drift tube comprises a double jacket design; an external stainless steel chamber encompassing an internal insulating tube housing the electrode stack and buffer gas. Copper tubing arranged in a longitudinal direction is situated between the two jackets. The copper tubing extends beyond the drift region and is connected to the house $\mathrm{N}_{2}$ gas-supply which is passed through liquid nitrogen to generate a coolant. 
Fine tuning of the $\mathrm{N}_{2}$ flow rate determines the flow of coolant through the tubing surrounding the drift cell and therefore allows control of the drift gas temperature to $\pm 1 \mathrm{~K}$ (see Error! Reference source not found.S1). Arrival time distributions were acquired over a range of drift voltages (290 - $220 \mathrm{~V})$ before being converted to CCS distributions as described previously ${ }^{24}$.

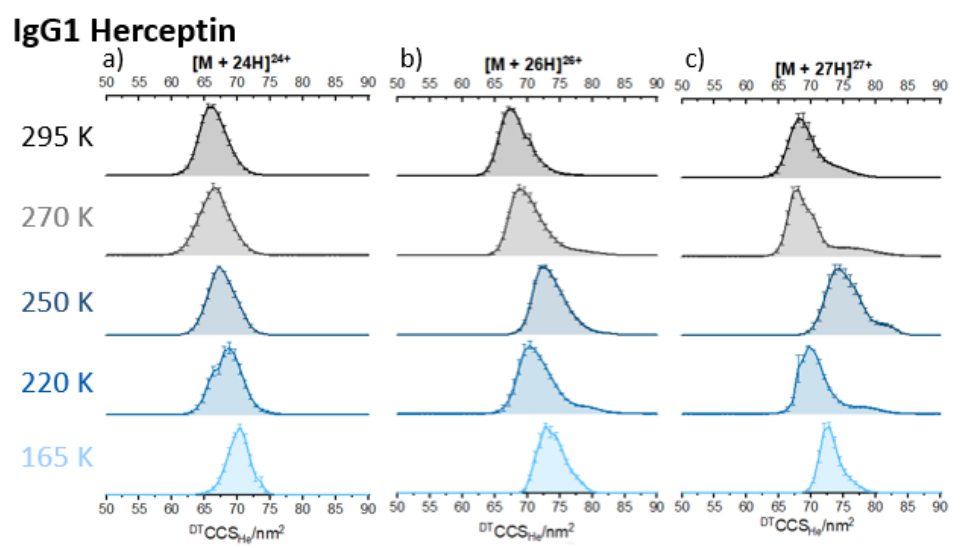

\section{IgG2 GMP3}
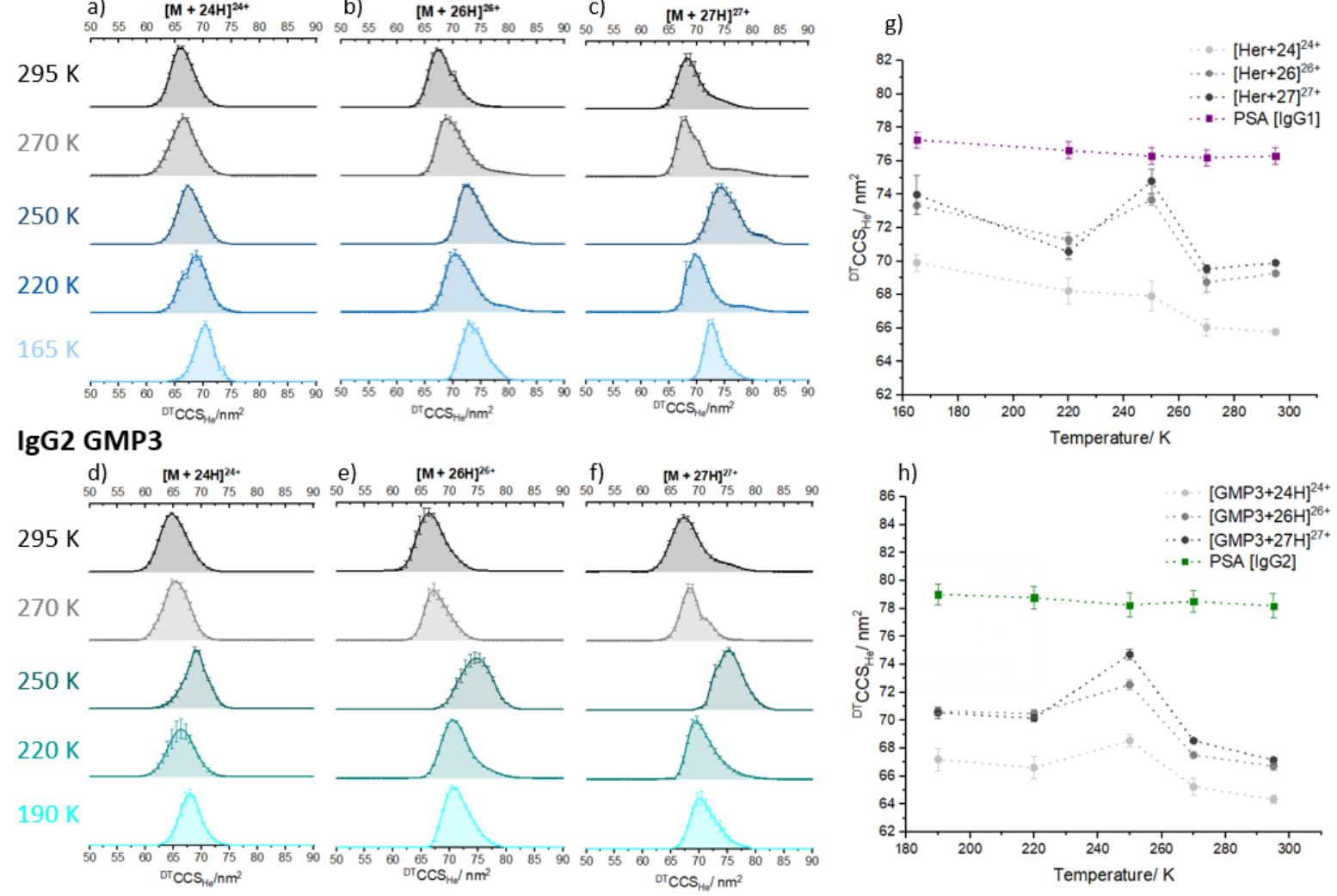

Figure 2. Collision cross section distributions $\left({ }^{\mathrm{DT}} \mathrm{CCSD}_{\mathrm{He}}\right)$ for $(\mathrm{a})[\mathrm{Her}+24 \mathrm{H}]^{24+}$, (b) $[\mathrm{Her}+26 \mathrm{H}]^{26+}$ and $(\mathrm{c})[\mathrm{Her}+27 \mathrm{H}]^{27+}$ charge state ions of Herceptin at five temperatures from 295 to $165 \mathrm{~K}$; and (d) $[\mathrm{GMP} 3+24 \mathrm{H}]^{24+}$, (e) $[\mathrm{GMP} 3+26 \mathrm{H}]^{26+}$ and (f) $[\mathrm{GMP} 3+27 \mathrm{H}]^{27+}$ charge state ions of GMP3 at five temperatures from 295 to $190 \mathrm{~K}$. Error bars correspond to the standard deviation from three, 3 minute long acquisitions. Projection Superposition Approximation (PSA) ${ }^{30,31,32,33}$ Calculated CCS values ( ${ }^{\text {CALC }}$ CCS PSA) are shown for Herceptin in g) (purple squares) and for GMP3 in h) (green squares), with experimental ${ }^{\mathrm{D}} \mathrm{CCS}_{\mathrm{He}}$ values for $\left.[\mathrm{M}+24 \mathrm{H}]\right]^{24+}$, $[\mathrm{M}+26 \mathrm{H}]^{26+}$ and $[\mathrm{M}+27 \mathrm{H}]^{27+}$ (light grey circles, grey circles and dark grey circles, respectively).

VT IM-MS data was obtained for three mAbs over the temperature range $295 \mathrm{~K}-165 \mathrm{~K}$. Initial room temperature CCS distributions are in line with previous measurements ${ }^{34,35}$. We observe a more restricted CCS distribution for IgG2, demonstrating lower flexibility compared with IgG1 and NIST mAb. Further details and discussion of room temperature measurements for Herceptin (IgG1), GMP3 (IgG2) and NIST mAb (Figures S2 and S3) is contained in the supplementary information. Figure 2 depicts the 
collision cross section data for selected charge states of IgG1 and IgG2, in the forms of ${ }^{\mathrm{DT} C C S} \mathrm{He}$ distributions (Figure 2 a-f) and apex values (Figure 2g, h). For all ions the ${ }^{\mathrm{DT}} \mathrm{CCS}_{\mathrm{He}}$ increases as a function of reduced temperature, in line with theory. ${ }^{36}$ The magnitude of the CCS for each charge state at all temperatures is different, with the higher charge states corresponding to larger forms of the protein (Figure S2). This can be explained in terms of the charge inparted by the $\mathrm{nESI}$ process sampling different conformational distributions. ${ }^{37}$ For Herceptin, comparing measurements taken at $295 \mathrm{~K}$ with $165 \mathrm{~K}$, we observe an increase in ${ }^{\mathrm{DT}} \mathrm{CC} \mathrm{S}_{\mathrm{He}}$ of $\sim 6 \%$ for all charge states. For GMP3 we observe similar overall increases for each charge state of $\sim 5 \%$ from 295 to $190 \mathrm{~K}$. It is also notable that the CCS distribution at $165 \mathrm{~K}$ is substantially narrower, indicating higher resolution at this cryogenic temperature.

Whilst the overall effect of lowered temperature is to increase the CCS, at $250 \mathrm{~K}$ there is an interesting exception to this predicted trend, particularly for the higher charge states. The theory for the transport of ions in gases does not permit any prediction to be made that there should be significant differences in the ion-neutral interaction potentials for each charge state at a given temperature, ${ }^{38}$ although the resolution will increase as the temperature is lowered $\left(R_{\max } \alpha 1 / \sqrt{T}\right) \cdot{ }^{39}$ Here at $250 \mathrm{~K}$ we observe a larger than predicted increase in ${ }^{\mathrm{D}} \mathrm{CCS}_{\mathrm{He}}$, and significant broadening of the distribution of conformers. Notably the effects are more pronounced for higher charge states, with the ${ }^{\mathrm{DT} C C \mathrm{~S}_{\mathrm{He}} \text { of }}$ $[\mathrm{Her}+24 \mathrm{H}]^{24+}$ increasing by $4 \%$ from $295 \mathrm{~K}$ to $250 \mathrm{~K}$, whereas for $[\mathrm{Her}+27 \mathrm{H}]^{27+}$ the increase is $7 \%$. For IgG2 the effect is even more apparent, $\triangle{ }^{D T C C S} \mathrm{He}_{\mathrm{e}}$ is $+6 \%$ for $[\mathrm{GMP}+24 \mathrm{H}]^{24+}$ and $+11 \%$ for $[\mathrm{GMP}+27 \mathrm{H}]^{27+}$. It has been observed in previous work that higher charge states unfold more readily due to a lower energy barrier between folded and unfolded states, ${ }^{4041}$ and here we are likely observing a similar effect when comparing higher and lower charge states.

These observations can be explained by the existence of conformational ensembles which are more variable at higher charge states and differently affected by the low temperatures. Some of the dehydrated conformers that populate the higher charge states yield ${ }^{\mathrm{DT}} \mathrm{CCS} \mathrm{S}_{\mathrm{He}}$ values that are much larger than predicted. There is a significant increase in the full width half height maximum (FWHM) of the $[\mathrm{Her}+27 \mathrm{H}]^{27+}{ }^{\mathrm{DT}} \mathrm{CCSD} \mathrm{He}$ at $250 \mathrm{~K}$. These observations indicate restructuring of the conformers to more extended states at $250 \mathrm{~K}$, which is in good agreement with previous predictions of cold denaturation for mAbs in solution. ${ }^{42}$ 
For the NIST mAb, we also observed comparable increases in ${ }^{\mathrm{DT}} \mathrm{CCS} \mathrm{Se}_{\mathrm{He}}$ with decreasing temperature (Error! Reference source not found.S5). Higher charge states of this mAb possess a significant population of more extended conformers at $295 \mathrm{~K}$ (Error! Reference source not found.S3a) and the relative increase in ${ }^{\mathrm{DT}} \mathrm{CCSD}$ He width at $250 \mathrm{~K}$ is a lot more subtle, $c f$. that found for Herceptin and GMP3. This implies that when a dehydrated mAb occupies a larger conformational range at room temperature, it is less prone to cold denature and that the effects that we observe are representative of the desolvated structure, which is in turn reliant on the non-covalent interactions dictated by the primary sequence.

Before we start to consider why this conformational effect is indeed dependent on the dehydrated tertiary fold we note that for each mAb their mass spectra (SI Figure S4) are unchanged as a function of temperature. We also observe only minor differences in the associated salt retention, based on the width of the MS signals; thereby discounting adduct effects upon the ${ }^{\mathrm{DT}} \mathrm{CCS}_{\mathrm{He}}$ distributions. To quantify the extent of the increase in CCS at $250 \mathrm{~K}$ we compare temperature-dependant experimental ${ }^{{ }^{\top} \mathrm{CCS}} \mathrm{He}$ values with theoretical Projection Superposition Approximation calculations ( ${ }^{\mathrm{CALC}} \mathrm{CCS} \mathrm{Se}_{\mathrm{He}}$ ) on dehydrated $\mathrm{mAbs}^{43}$. CCS calculations were performed using PSA CCS calculation webserver. ${ }^{30,31,32,33}$ The PSA values are shown in Figure $2(\mathrm{~g})$ and $(\mathrm{h})$ and whilst they indeed show the expected increase in CCS as the drift gas temperature is lowered, the difference between 295 and $250 \mathrm{~K}$ is minimal, far less than observed experimentally. We also note here that the magnitude of the increase between 295 and 165 $\mathrm{K}$ is lower in the theoretical model than experiment.

Summing the collision cross section distributions for each charge state allows the magnitude of this structural deformation at $250 \mathrm{~K}$ on the entire conformational ensemble to be visualised (Figure 3) and (Figure S6). Herceptin and GMP3, at $295 \mathrm{~K}$ each present two dominant conformational families. At the lowest temperature sampled (160K) the relative population of each conformer is highly similar to that at $295 \mathrm{~K}$ (Figure S6), albeit with an increase predicted by theory (although the magnitude appears greater than predicted by the PSA model (Figure $2 \mathrm{~g}$ and $\mathrm{h}$ ) $30,31,32,33$. This indicates that the dehydrated structures do not alter substantially when plunged into the drift cell at near cryogenic temperatures, and that we need to revise the theoretical understanding of the effect of temperature on CCS. This means that ion mobility data taken at different temperatures may act as a reference set for cryo-EM structures as well as provide insights for DEER measurements. In fact, cryo-EM has some limitations in examining antibodies due to their relatively low molecular weight and highly flexible structure, ${ }^{44}$ demonstrating that VT-IMS can provide unique structural information for antibodies at cryogenic temperatures. By contrast, 
the CCS distribution at $250 \mathrm{~K}$ is markedly different and much larger in magnitude, we have also noted this for lysozyme. ${ }^{45}$ For GMP3 the percentage occupancy of conformer (II) is substantially greater at $250 \mathrm{~K}$. This is also the case with Herceptin although not as marked. (Figure 3, SI Figure S6 g-h) The increase in apex ${ }^{\mathrm{DT} C C S}$ He is $10 \%$ from peak I to III and $11 \%$ from peak II to IV for the GMP3 sample. This suggests that for GMP3 (IgG2) at $250 \mathrm{~K}$, a greater proportion of the ions restructure to occupy more extended conformations than with Herceptin.

The VT-IMS data presented here show clear evidence of cold denaturation of Herceptin and GMP3 antibodies at $250 \mathrm{~K}$. These gas phase measurements agree with studies performed in solution, ${ }^{42}$ which raises the question is cold denaturation a phenomena that occurs independent of solvent?
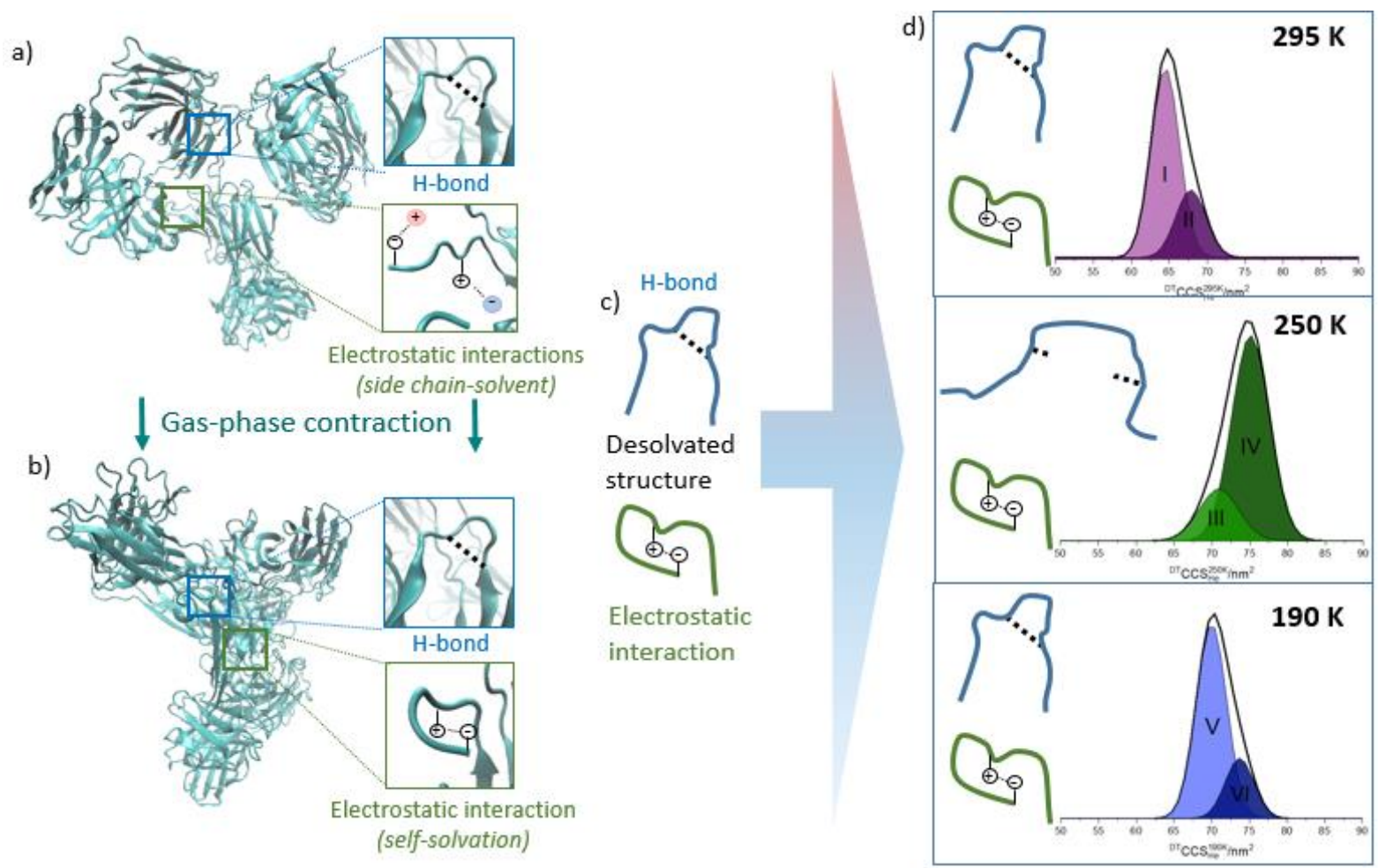

Figure 3: Schematic representation of structural changes that occur upon dehydration and ion mobility measurements at low temperature for IgG2. Ribbon diagrams show a) the starting solution structure and b) the energy minimised gas phase structure ${ }^{43}$ of IgG2. Examples of hydrogen bonds (blue boxes) and electrostatic interactions (green boxes) are shown for solution conformers (a) and the dehydrated form (b). The entire conformational ensemble is then placed in the drift cell at three different temperatures and the effect on the dominant non-covalent interactions (c) is shown in d) along with the summed ${ }^{\mathrm{DT}} \mathrm{CCS}_{\mathrm{He}}$ distributions for GMP3 at $295 \mathrm{~K}, 250 \mathrm{~K}$ and $190 \mathrm{~K}$ fitted with Gaussian functions for two conformers at each temperature. 
Cold denaturation is a well-established characteristic of eukaryotic proteins. ${ }^{3,46,47}$, A consensus view is that cold denaturation occurs as water starts to freeze, which in turn lessens the hydrophilic stabilisation of the protein fold imparted by interactions between charged residues on the surface of the protein and bulk solvent. This is attributed to the lengthening and stiffening of water-water $\mathrm{H}$ bonding, which interrupts the attractive interaction of the protein hydrophilic with bulk solvent. ${ }^{46,48,49}$ The surprising aspect of the data presented here is that we observe cold denaturation in an environment deplete of bulk solvent, and hence we need to rationalise how a self-solvated dehydrated macromolecule can also undergo cold denaturation.

Figure 3 illustrates the effect on non-covalent interactions of the transition of a mAb from solution to gas phase (Figure $3 \mathrm{a}-\mathrm{b}$ ), and subsequently into a drift cell at a given temperature (Figure $3 \mathrm{c}$ ). During the $\mathrm{nESI}$ process, there are progressively fewer solvent molecules with which the protein side-chains can form stabilising interactions. One effect of this is that oppositely charged side-chains, in the absence of a buffer counter-ion, may form stabilising inter-molecular electrostatic interactions, causing an overall structural contraction of the solvated state. The $\mathrm{H}$-bonds that are present in secondary structural elements within the protein may also contract a little on desolvation also due to the removal of any solvent screening.

We hypothesise that, similarly to the freezing of water, lowering the temperature induces more rigid, extended hydrogen bonding (Figure 3d). When this effect is coupled to residual protein dynamics, at T $=250 \mathrm{~K}, \mathrm{H}$-bonds may extend so much that they are no longer stabilising and in the absence of any solvent, this results in regions such as beta sheets, becoming detached from one another. ${ }^{46}$ Coulombic theory provides no rationale for electrostatic bonds being altered by changes in temperature but the tightening on dehydration, may provide stiffer regions which are prone to decouple as the $\mathrm{H}$-bonds extend. The fact we observe these effects most strongly at $250 \mathrm{~K}$ suggests that the residual dynamics allow this to occur on the timescale at which the protein experiences the cooling. At lower temperatures the residual dynamics must be dampened sufficiently fast to prevent significant restructuring, hence we observe no change in the relative population of conformers (Figures 2, 3d and S6).

It is fairly well established in literature that cold denaturation occurs due the change in the solvated environment, water effectively becomes more hydrophobic as it cools, with fewer $\mathrm{H}$-bonds to the protein at lower $\mathrm{T}$, and furthering the solvation of hydrophobic regions, which in turn drives the unfolding of the 
protein. ${ }^{50,49}$ Our experiment indicates that the phenomenon of cold denaturation can also occur due to inherent interactions in the tertiary and quaternary structure, which has implications for the effect of cold temperature on dehydrated proteins in cold environments, and may explain why so called cold adaptive proteins are often disordered in solution with sequences that adapt to more rigid structures in cold dry environments.

Further insights are gained by comparing the behaviour of the $\lg G 1$ with the $\lg G 2$ mAbs. The main structural difference between these two sub-families is found in the hinge; IgG2 possesses a more disulfide bridges than $\lg G 1$ and consequently lower flexibility $\lg G 1 .{ }^{43}$ For $\lg \mathrm{G} 1$, the flexibility of the native structure of means that a wide range of conformations are sampled in the gas phase (Figure S6b). ${ }^{24,43}$ Conformers that present lower charge states of IgG1 are largely unaffected at $250 \mathrm{~K}$ (Figures 2a), but those in higher charge states show an increase in CCS to occupy more extended structures (Figures 2c). IgG2 behaves differently. The conformers presently over all charge states are affected by the cold and restructure to more extended forms (Figures S6d-f and h). We surmise that the low flexibility of this antibody means that conformers 'snap' away from the dehydrated folded state to more extended forms at $250 \mathrm{~K}$. This is not observed for IgG1 where we suggest the higher intrinsic dynamics mean that the non-covalent networks remain more able to preserve the dehydrated forms.

\section{Conclusions}

In conclusion, this study demonstrates how VT IM-MS data can provide unique insights into cold denaturation at a molecular level. For Herceptin (IgG1) and GMP3 (IgG2), comparing measurements taken with the drift gas at room temperature to measurements at $250 \mathrm{~K}$, we observe larger-thanexpected CCS values and a greater occupancy of more extended conformers, as well as broadening of the conformational distribution a phenomenon our earlier work on monomeric proteins has hinted at. At temperatures below $250 \mathrm{~K}$, the occupancy of conformers is very similar to that at room temperature, although the distributions are narrower suggesting that the protein ions are 'snap frozen' and no structural rearrangement can occur. All these factors act as clear evidence of cold denaturation of Herceptin and GMP3 in the absence of solvent at $250 \mathrm{~K}\left(-20^{\circ} \mathrm{C}\right)$

This evidence for cold denaturation in the absence of solvent implies that it the factors that governing it are intrinsic to the fold. The large positive heat capacity of unfolding drives cold 
denaturisation and whilst this has previously been attributed to solvent solute effects, it is clear than this can be driven from changes to the strength of non-covalent interactions. Our VT-IM-MS data implies that the primary sequence and consequent fold of a given protein can dictate its cold denaturation behaviour. It is remarkable that the cold denaturation in vacuo is dominant at $250 \mathrm{~K}$ which is what has been predicted in the solvated state. Future work will consider how this approach can inform our understanding of living systems that adapt to live in cold environments as well as provide reference structures for cryo-EM.

\section{Materials}

Herceptin was a gift from UCB Pharma and the NIST monoclonal antibody reference material 8671 was purchased from NIST. ${ }^{51}$ GMP3 IgG2 antibody was a gift from Allergan Biologics. Ammonium acetate was purchased from Fisher Scientific. Purified water was produced in-house using a Milli-Q Advantage A10 system. All samples were prepared at $1 \mathrm{mg} / \mathrm{ml}(\sim 5 \mu \mathrm{M})$ in $100 \mathrm{mM}$ ammonium acetate, pH 6.80 and desalted using micro Bio-Spin 6 columns (Bio-Rad) prior to analysis.

\section{Acknowledgements}

This work has been funded by a Research Impact Scholarship funded by alumni of the University of Manchester and Bristol-Myers Squibb for a CASE studentship awarded to EN, and a BBSRC Industrial Case Studentship awarded to RU in collaboration with Covance Laboratories. Instrumentation was supported by Waters Corp. MS Vision, EPSRC and BBSRC awards and a lot of hard work and sweat.

Keywords: Antibodies • Structure-activity relationships $•$ Variable-Temperature Ion Mobility $\bullet$ Cold Denaturation $•$ Protein folding

(1) Lopez, C. F.; Darst, R. K.; Rossky, P. J. Mechanistic Elements of Protein Cold Denaturation. J. Phys. Chem. B 2008, 112 (19), 5961-5967. https://doi.org/10.1021/jp075928t. 
Structural Biology of the Hydrophobic Effect in Protein Folding. Sci. Rep. 2016, 6 (May), 1-9.

https://doi.org/10.1038/srep28285.

(3) Privalov, P. L. Cold Denaturation of Protein. Crit. Rev. Biochem. Mol. Biol. 1990, 25 (4), 281-306.

https://doi.org/10.3109/10409239009090612.

(4) Georlette, D.; Blaise, V.; Collins, T.; D’Amico, S.; Gratia, E.; Hoyoux, A.; Marx, J. C.; Sonan, G.; Feller, G.; Gerday, C. Some like It Cold: Biocatalysis at Low Temperatures. FEMS Microbiol. Rev. 2004, 28 (1), 25-42.

https://doi.org/10.1016/j.femsre.2003.07.003.

(5) Siddiqui, K. S.; Cavicchioli, R. Cold-Adapted Enzymes. Annu. Rev. Biochem. 2006, 75, 403-433.

https://doi.org/10.1146/annurev.biochem.75.103004.142723.

(6) Gerday, C.; Aittaleb, M.; Bentahir, M.; Chessa, J. P.; Claverie, P.; Collins, T.; D’Amico, S.; Dumont, J.; Garsoux, G.; Georlette, D.; Hoyoux, A.; Lonhienne, T.; Meuwis, M. A.; Feller, G. Cold-Adapted Enzymes: From Fundamentals to Biotechnology. Trends Biotechnol. 2000, 18 (3), 103-107. https://doi.org/10.1016/S0167-7799(99)01413-4.

(7) Furhan, J. Adaptation, Production, and Biotechnological Potential of Cold-Adapted Proteases from Psychrophiles and Psychrotrophs: Recent Overview. J. Genet. Eng. Biotechnol. 2020, 18 (1). https://doi.org/10.1186/s43141-020-000537.

(8) Feller, G. Psychrophilic Enzymes: From Folding to Function and Biotechnology. Scientifica (Cairo). 2013, 2013, 1-28. https://doi.org/10.1155/2013/512840.

(9) Sykes, C. Time- and Temperature-Controlled Transport: Supply Chain Challenges and Solutions. Pharm. Ther. 2018, $43(3), 154-158$.

(10) Ammann, C. Stability Studies Needed to Define the Handling and Transport Conditions of Sensitive Pharmaceutical or Biotechnological Products. AAPS PharmSciTech 2011, 12 (4), 1264-1275. https://doi.org/10.1208/s12249-011-96840.

(11) Cascella, K.; Jollivet, D.; Papot, C.; Léger, N.; Corre, E.; Ravaux, J.; Clark, M. S.; Toullec, J. Y. Diversification, Evolution and Sub-Functionalization of 70kDa Heat-Shock Proteins in Two Sister Species of Antarctic Krill: Differences in Thermal Habitats, Responses and Implications under Climate Change. PLoS One 2015, 10 (4), 1-23. https://doi.org/10.1371/journal.pone.0121642.

(12) Zerebecki, R. A.; Sorte, C. J. B. Temperature Tolerance and Stress Proteins as Mechanisms of Invasive Species Success. PLoS One 2011, 6 (4), 1-7. https://doi.org/10.1371/journal.pone.0014806.

(13) Sanfelice, D.; Temussi, P. A. Cold Denaturation as a Tool to Measure Protein Stability. Biophys. Chem. 2016, 208, 48. https://doi.org/10.1016/j.bpc.2015.05.007.

(14) Yan, R.; DeLos Rios, P.; Pastore, A.; Temussi, P. A. The Cold Denaturation of IscU Highlights Structure-Function Dualism in Marginally Stable Proteins. Commun. Chem. 2018, 1 (1), 1-7. https://doi.org/10.1038/s42004-018-0015-1. 
Natl. Acad. Sci. 1988, 85 (10), 3343-3347. https://doi.org/10.1073/pnas.85.10.3343.

(16) Kitahara, R.; Okuno, A.; Kato, M.; Taniguchi, Y.; Yokoyama, S.; Akasaka, K. Cold Denaturation of Ubiquitin at High Pressure. Magn. Reson. Chem. 2006, 44 (7 SPEC. ISS.), 108-113. https://doi.org/10.1002/mrc.1820.

(17) Liu, D.; Wyttenbach, T.; Carpenter, C. J.; Bowers, M. T. Investigation of Noncovalent Interactions in Deprotonated Peptides: Structural and Energetic Competition between Aggregation and Hydration. J. Am. Chem. Soc. 2004, 126 (10), 3261-3270. https://doi.org/10.1021/ja0393628.

(18) Breuker, K.; Mclafferty, F. W. Electrospray Into the Gas Phase, $10 \% 12$ To 102 S. Proc. Natl. Acad. Sci. 2008, 105 (47), 18145-18152.

(19) Kemper, P. R.; Bowers, M. T. A Hybrid Double-Focusing Mass Spectrometer-High-Pressure Drift Reaction Cell to Study Thermal Energy Reactions of Mass-Selected lons. J. Am. Soc. Mass Spectrom. 1990, 1, 197-207. https://doi.org/10.1016/1044-0305(90)85036-L.

(20) Wyttenbach, T.; Bowers, M. Design of a New Electrospray lon Mobility Mass Spectrometer. Int J Mass Spectrom 2001, $212(1-3), 13-23$.

(21) McCullough, B. J.; Kalapothakis, J.; Eastwood, H.; Kemper, P.; MacMillan, D.; Taylor, K.; Dorin, J.; Barran, P. E. Development of an Ion Mobility Quadrupole Time of Flight Mass Spectrometer. Anal. Chem. 2008, 80 (16), 63366344. https://doi.org/10.1021/ac800651b.

(22) May, J. C.; Russell, D. H. A Mass-Selective Variable-Temperature Drift Tube Ion Mobility-Mass Spectrometer for Temperature Dependent Ion Mobility Studies. J. Am. Soc. Mass Spectrom. 2011, 22, 1134-1145.

https://doi.org/10.1007/s13361-011-0148-2.

(23) Mason, E. A.; McDaniel, E. W. Temperature Dependence on Mobility. In Transport Properties of lons in Gases; John Wiley \& Sons Ltd., 1988; pp 245-254. https://doi.org/10.1002/3527602852.

(24) Pacholarz, K. J.; Porrini, M.; Garlish, R. A.; Burnley, R. J.; Taylor, R. J.; Henry, A. J.; Barran, P. E. Dynamics of Intact Immunoglobulin G Explored by Drift-Tube Ion-Mobility Mass Spectrometry and Molecular Modeling. Angew. Chemie Int. Ed. 2014, 53 (30), 7765-7769. https://doi.org/10.1002/anie.201402863.

(25) Tian, Y.; Han, L.; Buckner, A. C.; Ruotolo, B. T. Collision Induced Unfolding of Intact Antibodies: Rapid Characterization of Disulfide Bonding Patterns, Glycosylation, and Structures. Anal. Chem. 2015, 87, 11509-11515. https://doi.org/10.1021/acs.analchem.5b03291.

(26) Tian, Y.; Ruotolo, B. T. Collision Induced Unfolding Detects Subtle Differences in Intact Antibody Glycoforms and Associated Fragments. Int. J. Mass Spectrom. 2018, 425, 1-9.

(27) Bagal, D.; Valliere-Douglass, J. F.; Balland, A.; Schnier, P. D. Resolving Disulfide Structural Isoforms of IgG2 Monoclonal Antibodies by Ion Mobility Mass Spectrometry. Anal. Chem. 2010, 82 (16), 6751-6755. https://doi.org/10.1021/ac1013139.

(28) Pacholarz, K.; Peters, S. J.; Garlish, R. A.; Henry, A. J.; Taylor, R. J.; Humphreys, D. P.; Barran, P. E. Molecular 
Insights to the Thermal Stability of MAbs with Variable Temperature lon Mobility Mass Spectrometry. ChemBioChem 2016, 17, 46-51. https://doi.org/10.1002/cbic.201500574.

(29) Ujma, J.; Giles, K.; Morris, M.; Barran, P. E. New High Resolution Ion Mobility Mass Spectrometer Capable of Measurements of Collision Cross Sections from 150 to 520 K. Anal. Chem. 2016, 88 (19), 9469-9478. https://doi.org/10.1021/acs.analchem.6b01812.

(30) Bleiholder, C.; Wyttenbach, T.; Bowers, M. T. A Novel Projection Approximation Algorithm for the Fast and Accurate Computation of Molecular Collision Cross Sections (I). Method. Int J Mass Spectrom 2011, 308, 1-10.

(31) Bleiholder, C.; Contreras, S.; Do, D. T.; Bowers, M. T. A Novel Projection Approximation Algorithm for the Fast and Accurate Computation of Molecular Collision Cross Sections(II). Model Parameterization and Definition of Empirical Shape Factors for Proteins. Int J Mass Spectrom 2013, 345-347, 89-96.

(32) Anderson, S. E.; Bleiholder, C.; Brocker, E. R.; Stang, P. J.; Bowers, M. T. A Novel Projection Approximation Algorithm for the Fast and Accurate Computation of Molecular Collision Cross Sections (III). Application to Supramolecular Coordination-Driven Assemblies. Int J Mass Spectrom 2012, 330-332, 78-84.

(33) Bleiholder, C.; Contreras, S.; Bowers, M. T. A Novel Projection Approximation Algorithm for the Fast and Accurate Computation of Molecular Collision Cross Sections (IV). Application to Polypeptides. Int J Mass Spectrom 2013, 354 355, 275-280.

(34) Pacholarz, K. J.; Peters, S. J.; Garlish, R. A.; Henry, A. J.; Taylor, R. J.; Humphreys, D. P.; Barran, P. E. Molecular Insights into the Thermal Stability of MAbs with Variable-Temperature lon-Mobility Mass Spectrometry. ChemBioChem 2016, 17, 46-51. https://doi.org/10.1002/cbic.201500574.

(35) Pritchard, C.; Connor, G. O.; Ashcroft, A. E. The Role of lon Mobility Spectrometry - Mass Spectrometry in the Analysis of Protein Reference Standards. Anal. Chem. 2013, 85, 7205-7212.

(36) Wyttenbach, T.; Von Helden, G.; Batka, J. J.; Carlat, D.; Bowers, M. T. Effect of the Long-Range Potential on lon Mobility Measurements. J. Am. Soc. Mass Spectrom. 1997, 8 (3), 275-282. https://doi.org/10.1016/S10440305(96)00236-X.

(37) Beveridge, R.; Covill, S.; Pacholarz, K. J.; Kalapothakis, J. M. D.; Macphee, C. E.; Barran, P. E. A Mass-SpectrometryBased Framework To Define the Extent of Disorder in Proteins. Anal. Chem. 2014, 86 (22), 10979-10991.

(38) McDaniel, E. W.; Viehland, L. A. The Transport of Slow lons in Gases: Experiment, Theory, and Applications. Phys. Rep. 1984, 110, 333-367.

(39) St. Louis, R. H.; Hill Jr., H. H.; Eiceman, G. A. Ion Mobility Spectrometry in Analytical Chemistry. Crit. Rev. Anal. Chem. 1990, 21 (5), 321-355. https://doi.org/10.1080/10408349008050848.

(40) Hall, Z.; Politis, A.; Bush, M. F.; Smith, L. J.; Robinson, C. V. Charge-State Dependent Compaction and Dissociation of Protein Complexes: Insights from Ion Mobility and Molecular Dynamics. J. Am. Chem. Soc. 2012, 134 (7), 3429-3438. https://doi.org/10.1021/ja2096859. 
(41) Pacholarz, K. J.; Barran, P. E. Distinguishing Loss of Structure from Subunit Dissociation for Protein Complexes with Variable Temperature Ion Mobility Mass Spectrometry. Anal. Chem. 2015, 87 (12), 6271-6279.

https://doi.org/10.1021/acs.analchem.5b01063.

(42) Lazar, K. L.; Patapoff, T. W.; Sharma, V. K. Cold Denaturation of Monoclonal Antibodies. MAbs 2010, 2 (1), 42-52. https://doi.org/10.4161/mabs.2.1.10787.

(43) Hansen, K.; Lau, A. M.; Giles, K.; McDonnell, J. M.; Struwe, W. B.; Sutton, B. J.; Politis, A. A Mass-SpectrometryBased Modelling Workflow for Accurate Prediction of IgG Antibody Conformations in the Gas Phase. Angew. Chemie Int. Ed. 2018, 57 (52), 17194-17199. https://doi.org/10.1002/anie.201812018.

(44) Lei, D.; Liu, J.; Liu, H.; Cleveland, T. E.; Marino, J. P.; Lei, M.; Ren, G. Single-Molecule 3D Images of "Hole-Hole" IgG1 Homodimers by Individual-Particle Electron Tomography. Sci. Rep. 2019, 9 (1), 1-15. https://doi.org/10.1038/s41598019-44978-7.

(45) Ujma, J.; Jhingree, J.; Norgate, E. L.; Upton, R.; Wang, X.; Benoit, F.; Bellina, B.; Barran, P. E. Protein Unfolding in Freeze Frames: Intermediates of Ubiquitin and Lysozyme Revealed by Variable Temperature Ion Mobility-Mass Spectrometry. Preprint 2021, Under review.

(46) Jaenicke, R.; Heber, U.; Franks, F.; Chapman, D.; Griffin, M. C. A.; Hvidt, A.; Cowan, D. A. Protein Structure and Function at Low Temperatures [and Discussion]. Philos. Trans. R. Soc. B Biol. Sci. 1990, 326 (1237), 535-553. https://doi.org/10.1098/rstb.1990.0030.

(47) Privalov, P. L.; Griko, Y. V.; Venyaminov, S. Y. Cold Denaturation. J. Mol. Biol. 1986, 190, 487-498.

(48) Ben-Naim, A. Theory of Cold Denaturation of Proteins. Adv. Biol. Chem. 2013, 03 (01), 29-39. https://doi.org/10.4236/abc.2013.31005.

(49) Dias, C. L.; Ala-Nissila, T.; Wong-ekkabut, J.; Vattulainen, I.; Grant, M.; Karttunen, M. The Hydrophobic Effect and Its Role in Cold Denaturation. Cryobiology 2010, 60 (1), 91-99. https://doi.org/10.1016/j.cryobiol.2009.07.005.

(50) Matysiak, S.; Debenedetti, P. G.; Rossky, P. J. Role of Hydrophobic Hydration in Protein Stability: A 3D Water-Explicit Protein Model Exhibiting Cold and Heat Denaturation. J. Phys. Chem. B 2012, 116 (28), 8095-8104. https://doi.org/10.1021/jp3039175.

(51) NIST Monoclonal Antibody Reference Material 8671 